\title{
Caracterização microclimática de cavernas turísticas do Parque Nacional Cavernas do Peruaçu, Minas Gerais, Brasil
}

\section{Microclimatic characterization of tourist caves in Parque Nacional Cavernas do Peruaçu, Minas Gerais, Brazil}

\author{
Mauro Gomes 1 \\ Darcy José dos Santos ${ }^{2}$ (D) \\ Úrsula de Azevedo Ruchkys 3 (D) \\ Luiz Eduardo Panisset Travassos ${ }^{4}(\mathbb{D}$
}

\begin{abstract}
Palavras-chave:
Espeleoclima

Microclima cavernícola

Atmosfera cavernícola

Monitoramento climático
\end{abstract}

\begin{abstract}
Resumo
O ambiente cavernícola possui condições atmosféricas muito peculiares que influenciam diretamente a existência e manutenção do conjunto de elementos bióticos e abióticos, socioeconômicos e histórico-culturais representados pelas cavernas ou a elas associados. Nas cavernas onde são desenvolvidas atividades turísticas, a presença humana pode afetar o delicado equilíbrio destas condições. Esta pesquisa foi desenvolvida para caracterizar o microclima cavernícola de sete cavernas que integram o circuito turístico do Parque Nacional Cavernas do Peruaçu, localizado na região Norte do Estado de Minas Gerais, região sudeste do Brasil. Dados de temperatura e umidade relativa do ar foram coletados por 41 medidores automatizados que acumularam pouco mais de 110.300 registros cada um. A pesquisa se destaca por ser uma das únicas de longa duração (2017 à 2019) desenvolvida no país. A análise destas informações permitiu não apenas caracterizar o microclima das cavernas, mas também observar a relação destes atributos com a morfologia interna e com a posição que as cavidades se encontram em relação ao relevo cárstico da região. A metodologia desenvolvida por esta pesquisa poderá subsidiar o Programa de Monitoramento das Condições Ambientais das Cavernas a ser implementado pela gestão do Parque Nacional e a identificação de ambientes mais sensíveis no interior das cavernas permitirá o reordenamento da visitação a estes atrativos.
\end{abstract}

\begin{abstract}
The cave environment has very peculiar atmospheric conditions that directly influence the existence and maintenance of the set of biotic and abiotic, socioeconomic, and historical-cultural elements represented by the caves or associated with them. In caves where tourist activities are carried out, human presence can affect the delicate balance of these conditions. This research was developed to characterize the cave microclimate of seven caves that make up the tourist circuit of the Parque Nacional Cavernas do Peruaçu, located in the northern region of the State of Minas Gerais, in the southeastern region of Brazil. Temperature and relative humidity data were collected by 41 automated meters that accumulated just over 110,300 records each. The research stands out for being one of the only long-term (2017 to 2019) developed in the country. The analysis of this information allowed not only to characterize the microclimate of the caves, but also to observe the relationship of these attributes with the internal morphology and with the position that the caves are in relation to the region's karst relief. The methodology developed by this research can subsidize the
\end{abstract}

\footnotetext{
${ }^{1}$ Centro Nacional de Pesquisa e Conservação de Cavernas - CECAV, Nova Lima, MG, Brasil. mauro.gomes@icmbio.gov.br ${ }^{2}$ Centro Nacional de Pesquisa e Conservação de Cavernas - CECAV, Nova Lima, MG, Brasil. darcy.santos@icmbio.gov.br

${ }^{3}$ Universidade Federal de Minas Gerais, Belo Horizonte, MG, Brasil. tularuchkys@yahoo.com.br

${ }^{4}$ Pontifícia Universidade Católica de Minas Gerais, Belo Horizonte, MG, Brasil. luizepanisset@ gmail.com
} 
Environmental Conditions Monitoring Program of the Caves to be implemented by the management of the National Park and the identification of more sensitive environments inside the caves will allow the reorganization of the visitation to these attractions.

\section{INTRODUÇÃO}

O clima subterrâneo aos ser comparado com aquele observado na superfície pode, em um primeiro momento, transmitir a impressão de condições climáticas perfeitamente estáveis, sem ocorrência de flutuações meteorológicas ou sem variações sazonais ao longo do ano e que a temperatura se mantém constante ao longo de toda a extensão da caverna (BADINO, 2010). Entretanto, fatores intrínsecos às cavernas como confinamento espacial, ausência de luz, baixa incidência de energia solar, topografia e geometria interna, além da distribuição espacial das entradas (LOBO, 2012; TRAVASSOS, 2016) são capazes de promover significativos fluxos de energia e massa entre o meio subterrâneo e a superfície (CIGNA, 1993). Portanto, estas condições meteorológicas, assim como aquelas observadas no meio externo, são dinâmicas e ao adotarmos uma escala de análise adequada, é possível perceber as discretas variações que caracterizam o microclima das cavernas (BADINO, 2010).

As condições climáticas são muito peculiares no ambiente subterrâneo e exercem influência tanto na biota e gênese dos condutos e seus espeleotemas, quanto nos registros arqueológicos paleontológicos e culturais abrigados pelas cavernas. A interferência humana pode impactar diretamente a estabilidade deste ambiente, provocando alterações na temperatura ou na umidade relativa do ar (TOOMEY, 2009). Lobo (2012) ressalta que mudanças ocorridas no clima cavernícola em função do uso turístico podem vir a comprometer a preservação de pinturas rupestres, a constituição de espeleotemas e rochas, assim como o equilíbrio da biota subterrânea. Esta situação tem levado especialistas a desenvolverem estudos específicos sobre estes possíveis impactos negativos, sobretudo considerando aquelas cavernas abertas ao turismo (CALAFORRA et al., 2003; CIGNA, 1993; LOBO et al., 2015; PULIDO-BOSCH et al., 1997; ŠEBELA et al., 2013; ŠEBELA; TURK, 2014). No continente europeu, estudos com o propósito de aumentar o conhecimento a respeito do comportamento do microclima cavernícola em relação ao uso turístico têm sido realizados desde a primeira metade do século XX (ŠEBELA et al., 2013). No
Brasil, apesar de existirem registros mais antigos (décadas de 1960 e 1970), foi no final dos anos 1990 que Boggiani et al. (2007) desenvolveram um dos primeiros estudos sistematizados abordando o microclima de cavernas. Mas foi somente no início dos anos 2000 que as pesquisas nesta temática passaram a contar com maior aprimoramento de métodos, técnicas e equipamentos que possibilitaram a obtenção de séries mais longas e confiáveis de dados (LOBO, 2010). Assim, algumas cavernas turísticas do país passaram a contar com os estudos do microclima cavernícola para subsidiar as definições do seu plano de uso e manejo (LOBO, 2011; ROCHA, 2010; ROCHA; GALVANI, 2011; TRAVASSOS, 2010; VERÍSSIMO et al., 2003).

O Parque Nacional Cavernas do Peruaçu (PNCP) está localizado na região sudeste do Brasil, no norte do estado de Minas Gerais. Ele abriga algumas das mais importantes cavernas turísticas do país e segundo informações da equipe responsável pela gestão desta Unidade de Conservação (UC), o número de visitantes vem aumentando progressivamente nos últimos anos. O Plano de Manejo desta UC (IBAMA, 2005) determina o desenvolvimento de um Programa de Monitoramento das Condições Ambientais das Cavernas que até hoje não foi desenvolvido. Para o atendimento a esta demanda Gomes et al. (2019) e Santos et al. (2018) realizaram estudos preliminares envolvendo esta temática que serviram de base para a elaboração da presente pesquisa.

Este manuscrito tem por objetivo apresentar a caracterização microclimática de sete cavernas que integram o roteiro turístico do PNCP por meio da compilação e análise dos dados de temperatura e umidade relativa do ar coletados ao entre os anos de 2017 e 2019. Espera-se que as análises conduzidas neste trabalho possam fornecer à gestão do PNCP mais elementos a serem considerados tanto na definição da capacidade de carga, quanto na restrição de acesso dos visitantes às áreas internas das cavernas consideradas mais sensíveis a alterações microclimáticas. Além disso, considerando uma perspectiva mais abrangente, espera-se que a pesquisa possa oferecer subsídios para o aprofundamento do conhecimento sobre a dinâmica climática de cavernas em ambientes tropicais, especialmente aquelas abertas ao uso turístico. 


\section{MATERIAL E MÉTODOS}

\section{Área de estudo}

O PNCP é uma unidade de conservação de proteção integral criada com o objetivo de proteger os ecossistemas naturais inseridos no Vale Cárstico do rio Peruaçu (BRASIL, 1999). Possui uma área estimada de 56.800 ha e está localizado na porção norte do estado de Minas Gerais. (Figura 1). O parque está inserido na bacia do rio São Francisco, entre os municípios de Januária, Itacarambi e São João das Missões, a $653 \mathrm{~km}$ da capital do estado, Belo Horizonte (IBAMA, 2005). O conjunto natural do vale do rio Peruaçu, incluindo o cânion (vale cárstico), as cavernas e os sítios arqueológicos são reconhecidos nacional e internacionalmente como sendo um dos poucos locais no planeta a reunir todas estas características em um só lugar e de modo tão esplêndido. Além destes, o PNCP também comporta outros atributos extremamente relevantes, tanto do ponto de vista científico como natural, que fizeram com que o parque fosse indicado ao reconhecimento de Patrimônio da Humanidade da Organização das Nações Unidas (IBAMA, 2005).

Figura 1- Localização do Parque Nacional Cavernas do Peruaçu e das cavernas monitoradas.

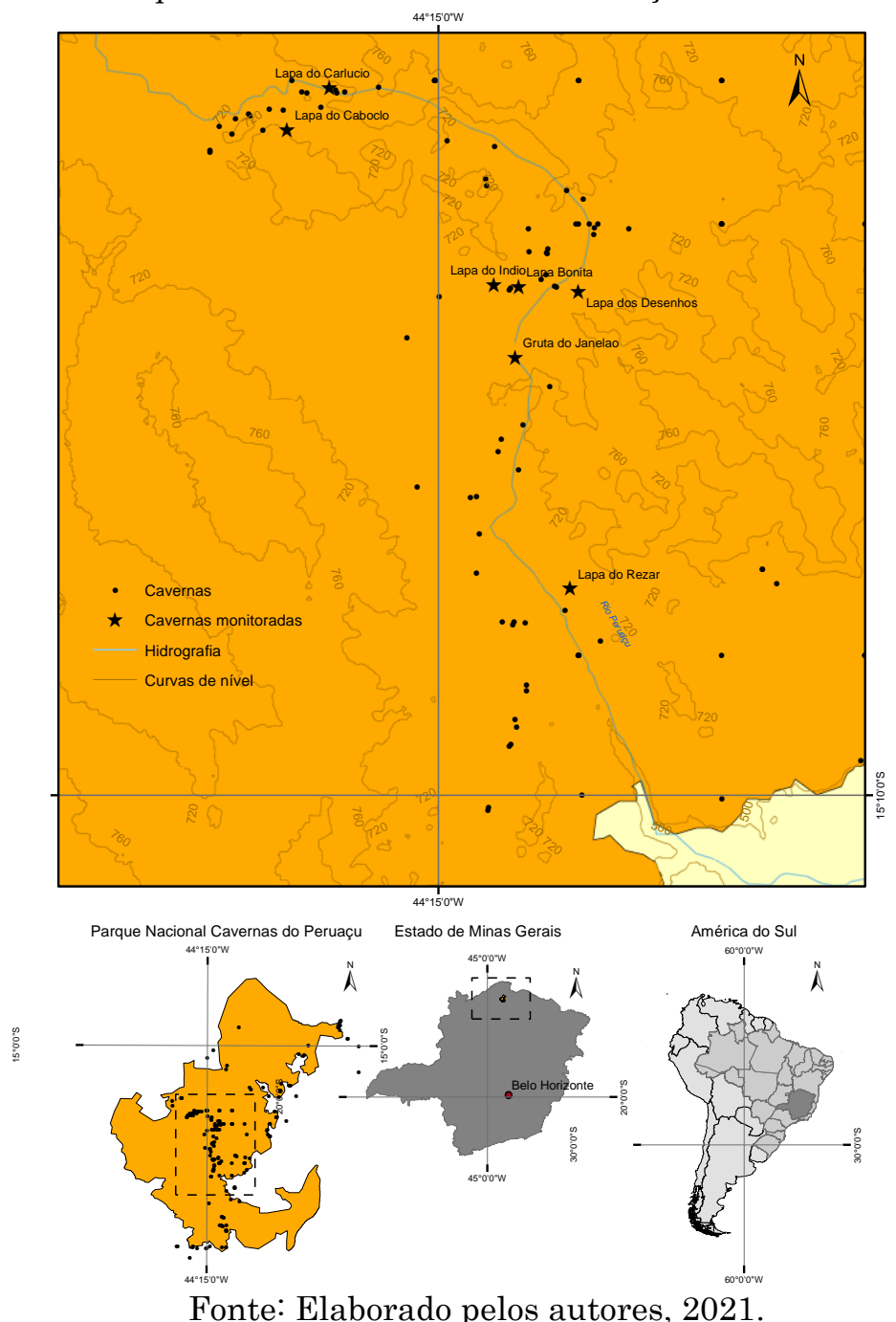

A unidade se encontra em área de transição entre os biomas cerrado e caatinga e em seu interior estão protegidos importantes fragmentos de Floresta Estacional Decidual (Mata Seca), Floresta Estacional Semidecidual, Floresta Perenifólia Ribeirinha, Formação Rupestre, Formações Savânicas, Formação Savânica-Estépica e Comunidades Aluviais
(IBAMA, 2005). No contexto geológico destacamse os afloramentos carbonáticos do Grupo Bambuí (Neoproterozóico) que em alguns lugares do parque estão parcialmente cobertos por rochas siliciclásticas do Mesozóico Superior, pertencentes à Formação Urucuia (SCHOBBENHAUS; NEVES, 2003). Durante o Paleogeno, a região passou por soerguimento 
tectônico e, paralelamente, uma ampla rede de condutos subterrâneos se desenvolveu em decorrência da circulação de água do aquífero cárstico. Já no Quaternário, a evolução do relevo cárstico levou ao desabamento de diversos segmentos de tetos de cavernas culminando com a abertura do Vale Cárstico do rio Peruaçu (KOHLER et al., 1989; MOURA, 1997; PILÓ, 1989).

Foram definidas quatro unidades morfológicas no parque (IBAMA, 2005) que se distribuem entre as cotas de $830 \mathrm{~m}$ a $440 \mathrm{~m}$ : (a) Planalto das Gerais; (b) Zona de Transição; (c) Compartimento Carstificado; (d) Depressão do São Francisco. O Compartimento do Planalto das Gerais compreende a unidade situada acima da cota $760 \mathrm{~m}$, desenvolvida sobre as rochas da Formação Urucuia. Possui relevo aplainado com ondulações suaves, amplos interflúvios e baixa densidade de drenagens. O Compartimento da Zona de Transição está situado entre as cotas $760 \mathrm{~m}$ e $720 \mathrm{~m}$. Apresenta relevo aplainado, com a presença de feições cársticas como morros tabulares residuais e dolinas de subsidência lenta, caracterizando a transição entre o Planalto das Gerais e a sequência carbonática subjacente. O Compartimento Carstificado, situado entre $720 \mathrm{~m}$ e $500 \mathrm{~m}$ se desenvolve sobre os carbonatos do Grupo Bambuí. O relevo é acidentado e marcado pela descontinuidade da rede de drenagem. Este compartimento exibe grande quantidade e variedade de feições cársticas como cavernas, dolinas de abatimento, vales cársticos, maciços fissurados, torres ruiniformes, sumidouros, ressurgências, paredões, escarpados e caneluras de dissolução de variadas dimensões. O Compartimento da Depressão do São Francisco se encontra entre as cotas $500 \mathrm{~m}$ e $440 \mathrm{~m}$, possui relevo aplainado com ondulações suaves e a presença de dolinas de subsidência e morros testemunho de rochas carbonáticas do Grupo Bambuí.
A maioria das cavernas da região do Peruaçu é encontrada entre as cotas $750 \mathrm{~m}$ e $500 \mathrm{~m}$ no chamado Planalto Cárstico do São Francisco, onde ocorrem as sequências supracrustais carbonáticas (dolomitos e calcários) do Neoproterozóico pertencentes ao Grupo Bambuí. $\mathrm{O}$ rio Peruaçu vem modificando a paisagem ao longo do tempo, construindo um imponente cânion em seu caminho em direção ao rio São Francisco. Em função deste processo, os seguidos abatimentos de teto e paredes dos condutos do aquífero cárstico proporcionaram o aparecimento de amplas cavernas de dissolução e abatimento (PILÓ; RUBBIOLI, 2002).

Até o ano de 2020 a UC possuía pouco mais de 150 cavernas cadastradas na base de dados oficial do governo brasileiro (CECAV, 2021). Deste total, onze foram selecionadas para visitação pública e integradas a seis roteiros turísticos conforme o plano de manejo da unidade (IBAMA, 2005). É importante destacar que apesar dos registros incipientes, a atividade de visitação às cavernas do parque vem crescendo a cada ano. Segundo informações da administração da UC, foi registrada uma média de 330 visitantes/mês no ano de 2016 em 2018 este número já havia subido para 682 visitantes/mês.

Esta pesquisa se refere ao monitoramento da temperatura e da umidade relativa do ar no interior de sete cavernas que estão inseridas nos roteiros que recebem o maior número de turistas anualmente (Tabela 1). Foram selecionadas tanto cavidades que recebem turistas em seu interior, como a Gruta do Janelão, Lapa Bonita, Lapa do Carlúcio e Lapa do Rezar, quanto cavernas em que os visitantes acessam somente a parte externa, em áreas próximas às entradas como a Lapa dos Desenhos, Lapa do Índio e Lapa do Caboclo. 
Tabela 1 - Cavernas do roteiro turístico do PNCP atualmente monitoradas com as respectivas quantidades de estações automatizadas de medição.

\begin{tabular}{lccc}
\hline \multicolumn{1}{c}{ Caverna } & Altitude (m) & Projeção Horizontal (m) & Estações \\
Lapa do Caboclo & 698 & 100 & 4 \\
Gruta do Janelão & 686 & 4.740 & 5 \\
Lapa do Índio & 678 & 150 & 5 \\
Lapa do Carlúcio & 677 & 160 & 6 \\
Lapa do Rezar & 639 & 380 & 5 \\
Lapa Bonita & 638 & 420 & 10 \\
Lapa dos Desenhos & 619 & 140 & 6
\end{tabular}

Fonte: Adaptado de IBAMA (2005).

A Gruta do Janelão está inserida no grupo das cavernas drenadas pelo rio Peruaçu. Suas principais características são as amplas galerias que chegam a medir $100 \mathrm{~m}$ de altura e outros $100 \mathrm{~m}$ de largura em determinados pontos. Os condutos apresentam seções retangulares, geralmente únicas e com padrão planimétrico sinuoso. Também chamam a atenção as grandes claraboias que proporcionam a instalação de formações vegetais no interior da caverna. As demais cavernas citadas nesta pesquisa compõem o grupo das cavernas secas, desconectadas do aquífero cárstico. As Lapas dos Desenhos, Rezar, Caboclo, Bonita, Índios e Carlúcio, estão posicionadas acima do atual nível de base representado pelo rio Peruaçu e se inserem nos paredões do cânion principal ou em vales secos secundários. Estas cavernas apresentam padrão de desenvolvimento retilíneo e anguloso, com seções predominantemente retangulares (IBAMA, 2005).

Uma característica comum a todas as cavernas desta pesquisa é a presença da Mata Seca próximo às entradas, apresentando espécies arbóreo-arbustivas decíduas. A cobertura vegetal encontrada no entorno das cavernas pode ser observada sob duas formas distintas em função da cobertura pedológica e da maior umidade: ora apresenta composição florística semelhante à Mata Atlântica, ora apresenta alguns elementos da Mata Mesófila, Atlântica e da Caatinga (IBAMA, 2005).

\section{Instalação e configuração dos equipamentos}

Para registro dos dados de temperatura e umidade foram utilizadas estações automatizadas de medição, modelo Testo $175^{-}$ $\mathrm{H} 2$ (resolução: $0,1^{\circ} \mathrm{C}$ para temperatura e $0,1 \%$ para umidade relativa; acurácia: $0,1^{\circ} \mathrm{C}$ para temperatura e $0,3 \%$ para umidade relativa) configurados para realizar o registro dos dados a cada 10 minutos. Todos os equipamentos foram posicionados a uma altura média de 1,5 metros do piso e nas cavernas que recebem visitação em seu interior, preferencialmente em locais próximos àqueles destinados a passagem dos turistas.

Com base no mapa topográfico de cada caverna (IBAMA, 2005) foi definida uma malha de pontos e nestes locais foram realizadas três seções de coleta de dados de temperatura e umidade em datas distintas, utilizando o medidor multifunção ITMP 600. Posteriormente estes dados foram interpolados por meio da Ponderação do Inverso da Distância (IDW) em ambiente Geographic Information Sistem (GIS), que possibilitaram a elaboração de mapas que permitiram identificar as diferentes zonas climáticas das cavidades. A partir da leitura destes mapas, foram definidos ambientes distintos dentro das cavernas considerando também a morfologia dos condutos, a posição e a distribuição das entradas. A disposição espacial dos equipamentos considerou a existência de caminhamentos internos a serem utilizados pelos visitantes e priorizou a coleta de dados nas zonas heterotérmica (próxima à entrada), homeotérmica (zonas mais profundas) e nas zonas transacionais insaturadas (LOBO, 2012).

A definição dos locais para instalação dos equipamentos considerou o emprego de práticas de mínimo impacto, buscando-se posicionar as estações sem a necessidade de realização de furos nas estruturas da caverna. Para esta operação optou-se pela utilização de cabos de aço e clips de fixação que possibilitaram acomodar os medidores em espeleotemas, em fraturas ou saliências da rocha (Figura 2a). Para as cavernas que recebem visitação turística em seu interior, foi observado o posicionamento dos 
medidores em pontos próximos à local de passagem dos turistas (Figura 2b). O mesmo tipo de equipamento foi instalado também na parte externa da Gruta do Janelão e da Lapa Bonita (Figura 2c) em local próximo às entradas, a fim de se obter referências mais específicas das condições climáticas externas. Para esta situação foram construídos pequenos abrigos meteorológicos para a proteção dos medidores (Figura 2d).

Figura 2 - Instalação das estações de medição na Lapa Bonita. a) Fixação do equipamento em espeleotema, b) Medidor instalado próximo ao local de passagem dos turistas, c) Fixação do equipamento em árvore localizada próximo à entrada da caverna, d) Abrigo meteorológico instalado no medidor externo.

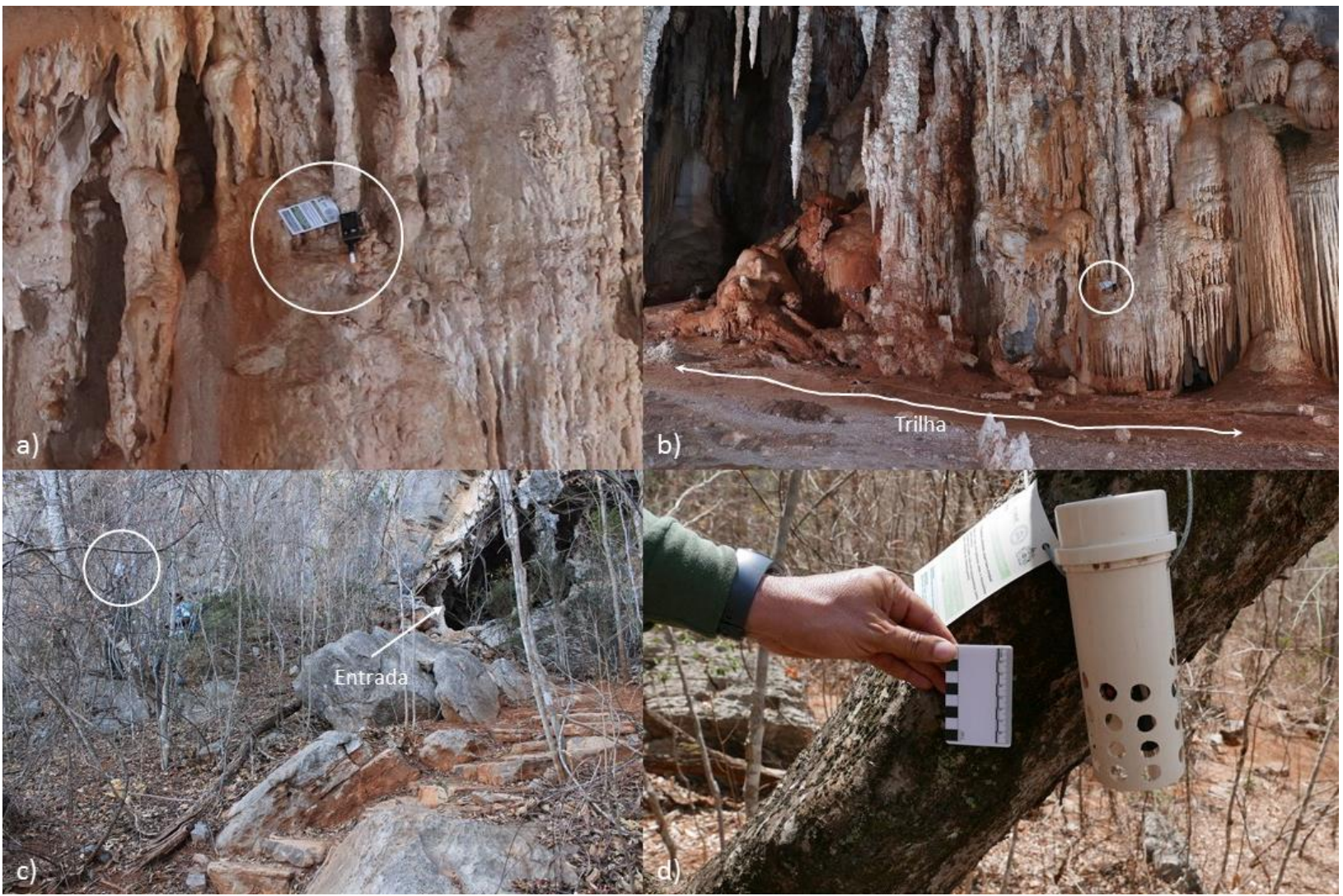

Fonte: Autores, 2021.

Cada estação recebeu uma identificação alusiva não só à caverna na qual se encontra instalada, mas também referente a disposição espacial da sua localização em relação a entrada da cavidade. Desta forma, o sufixo 1 indica a estação posicionada imediatamente depois da entrada da caverna e sufixos 6, ou 9 por exemplo, estações instaladas no último salão, na extremidade oposta à entrada. Desta forma, a identificação CAR1, indica o equipamento instalado logo após a entrada da Lapa do Carlúcio e BON9, o medidor instalado no último salão da Lapa Bonita. O sufixo “zero" se refere aos dois equipamentos externos, instalados próximos às entradas da Lapa Bonita (BON0) e Gruta do Janelão (JAN0).

\section{RESULTADOS E DISCUSSÃO}

Os mapas produzidos pela interpolação dos dados climáticos internos, juntamente com as informações morfológicas e de uso turístico de cada caverna foram empregados na definição dos locais que receberiam as estações automatizadas. Estes mapas permitiram identificar as condições de temperatura (Figura 3a) e umidade relativa do ar (Figura 3b) nos diferentes ambientes das cavidades nas três campanhas de campo ocorridas no início do projeto em 2017. 
Figura 3 - Mapas apresentando resultado da interpolação dados que subsidiaram a escolha dos locais para instalação das estações automatizadas na Lapa Bonita. a) Temperatura e b) Umidade relativa do ar.

a)

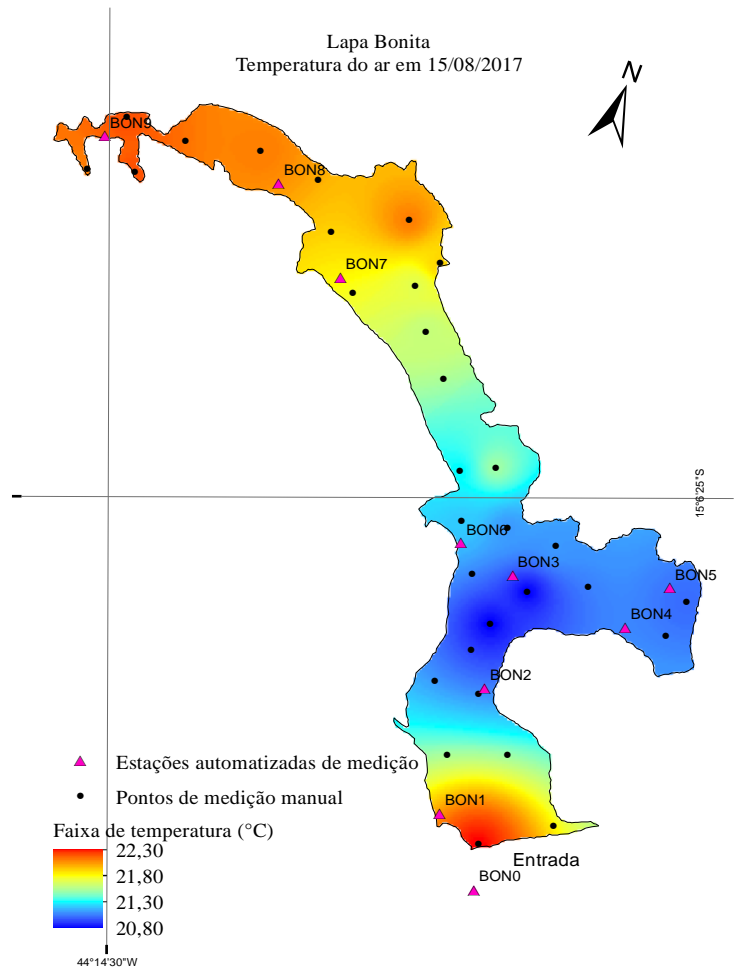

b)

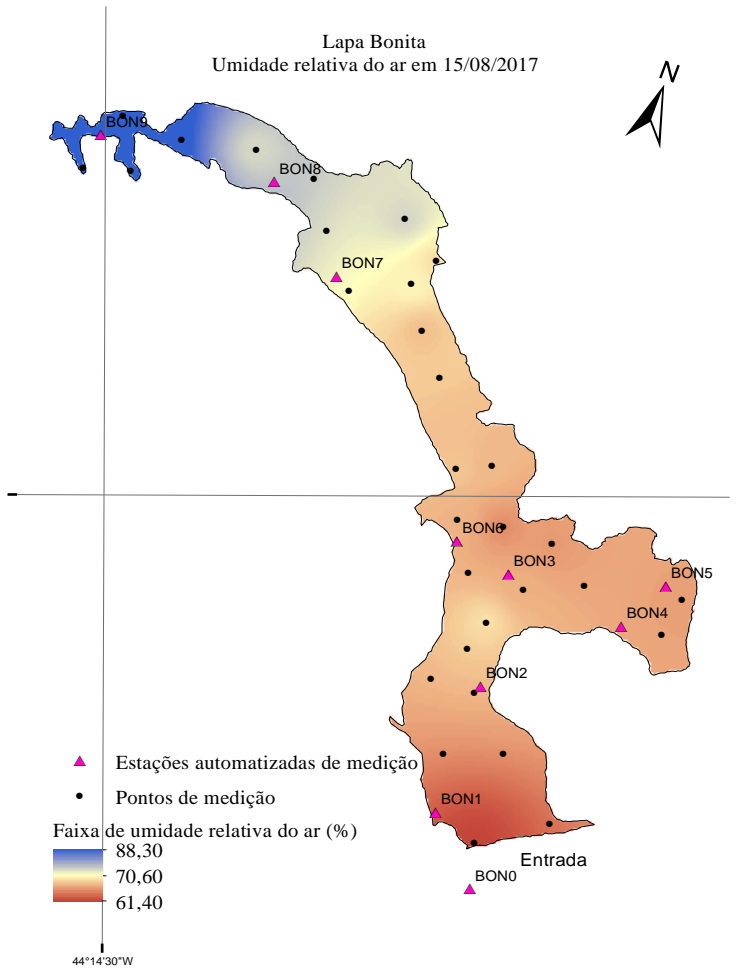

Fonte: Elaborado pelos autores, 2021.

Na coleta de dados realizada na Lapa Bonita em 15/08/2017 as temperaturas mais altas foram registradas nas regiões extremas da caverna, próximo à entrada $\left(22,3^{\circ} \mathrm{C}\right)$ e no último salão $\left(22,1^{\circ} \mathrm{C}\right)$ (Figura 3a). Também se observou que o salão localizado imediatamente após o salão de entrada foi a região mais fria da caverna, onde foi registrada a temperatura mais baixa $\left(20,8^{\circ} \mathrm{C}\right)$. Quanto à umidade relativa do ar, foi observado que a região da entrada apresentou o menor valor $(57,1 \%)$ e o último salão o valor mais elevado (88,3\%) (Figura $3 \mathrm{~b}$ ). Estas informações foram determinantes na identificação dos locais onde seria possível se registrar as variações climáticas associadas aos diferentes ambientes, bem como a influência que as condições externas exercem sobre o microclima cavernícola.

As cavernas monitoradas se encontram no Compartimento Carstificado, mais especificamente no Vale Cárstico formado pelo cânion do rio Peruaçu. De acordo com IBAMA (2005), o clima desta região é influenciado pelo processo de esculturação geomorfológica que favorece a canalização de ventos carregados de umidade provenientes, dentre outros lugares, do rio São Francisco. Este fator, associado à vegetação arbórea presente na região favorece um comportamento climático com temperaturas amenas, em torno de $24^{\circ} \mathrm{C}$, umidade relativa mais elevada, $80 \%$ em média, e baixas amplitudes.

Conforme observado por Lobo (2013) e Travassos (2016), o microclima subterrâneo é dependente das características intrínsecas das cavernas, tais como topografia, geometria, distribuição e quantidade de entradas, mas também recebe grande influência do ambiente externo. De acordo com IBAMA (2005), o Vale Cárstico onde as cavernas estão localizadas faz limite ao norte com o compartimento geomorfológico do Planalto dos Gerais de ambiente mais fresco e ligeiramente mais úmido e ao sul com o compartimento da Depressão do São Francisco de ambiente mais aquecido e menor umidade relativa (Serafini-Júnior, 2005).

O resultado da coleta dos dados realizada entre os anos de 2017 e 2019 estão dispostos na Tabela 2 que apresenta também a estatística descritiva dos valores das temperaturas registradas em cada uma das 41 estações instaladas nas cavernas do PNCP. Segundo Badino (2010), o ambiente cavernícola se apresenta mais estável do ponto de vista das 
condições climáticas devido as amplitudes relativamente baixas para temperatura e umidade interna ao ser comparado com o meio externo. Esta afirmação pode ser evidenciada ao observarmos os dados de amplitude da Tabela 2 . As estações BONO e JANO instaladas na parte externa das cavernas são as que apresentam os maiores valores de amplitude com os registros de $31,2^{\circ} \mathrm{C}$ e $29,8^{\circ} \mathrm{C}$, respectivamente. Quando se compara estes valores com aqueles registrados pelos equipamentos localizadas próximos às entradas, porém na parte interna destas cavernas, verifica-se que os valores de amplitude são significativamente menores, com $14,9^{\circ} \mathrm{C}$ para BON1 e $17,5^{\circ} \mathrm{C}$ para JAN1.

Tabela 2 - Estatística descritiva da temperatura nas estações das cavernas monitoradas.

\begin{tabular}{|c|c|c|c|c|c|c|c|}
\hline & $\begin{array}{c}\text { Estações } \\
\text { Automatizadas }\end{array}$ & Média & Desvio Padrão & Variância & Mínima & Máxima & Amplitude \\
\hline \multirow{6}{*}{ } & CAR1 & 20,7 & 2,57 & 6,59 & 9,5 & 29,5 & 20,0 \\
\hline & CAR2 & 21,1 & 2,09 & 4,35 & 11,3 & 26,0 & 14,7 \\
\hline & CAR3 & 20,9 & 2,13 & 4,53 & 11,0 & 25,0 & 14,0 \\
\hline & CAR4 & 21,3 & 2,39 & 5,69 & 9,9 & 27,0 & 17,1 \\
\hline & CAR5 & 21,3 & 1,66 & 2,75 & 15,0 & 24,4 & 9,4 \\
\hline & CAR6 & 21,1 & 1,55 & 2,4 & 14,0 & 24,9 & 10,9 \\
\hline \multirow{4}{*}{ 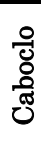 } & CAB1 & 22,9 & 1,86 & 3,46 & 13,6 & 26,8 & 13,2 \\
\hline & CAB2 & 23,0 & 1,53 & 2,34 & 14,6 & 26,0 & 11,4 \\
\hline & CAB3 & 24,0 & 0,96 & 0,91 & 20,1 & 27,5 & 7,4 \\
\hline & $\mathrm{CAB} 4$ & 24,4 & 0,7 & 0,5 & 22,4 & 28,3 & 5,9 \\
\hline \multirow{6}{*}{ 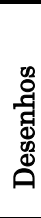 } & DES1 & 23,0 & 2,2 & 4,85 & 13,8 & 28,0 & 14,2 \\
\hline & DES2 & 23,7 & 1,13 & 1,28 & 19,1 & 26,6 & 7,5 \\
\hline & DES3 & 24,3 & 1,64 & 2,69 & 18,0 & 29,5 & 11,5 \\
\hline & DES4 & 24,2 & 1,08 & 1,16 & 20,2 & 27,5 & 7,3 \\
\hline & DES5 & 24,6 & 0,82 & 0,68 & 22,2 & 28,4 & 6,2 \\
\hline & DES6 & 24,3 & 0,8 & 0,63 & 21,8 & 28,6 & 6,8 \\
\hline \multirow{10}{*}{ 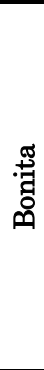 } & BONO & 23,6 & 4,54 & 20,56 & 9,2 & 40,4 & 31,2 \\
\hline & BON1 & 21,5 & 1,92 & 3,69 & 13,2 & 28,1 & 14,9 \\
\hline & BON2 & 20,0 & 1,39 & 1,94 & 12,8 & 22,1 & 9,3 \\
\hline & BON3 & 20,7 & 0,31 & 0,1 & 19,7 & 27,4 & 7,7 \\
\hline & BON4 & 20,7 & 0,26 & 0,07 & 20,1 & 23,7 & 3,6 \\
\hline & BON5 & 20,5 & 0,34 & 0,11 & 19,7 & 22,3 & 2,6 \\
\hline & BON6 & 20,4 & 0,36 & 0,13 & 19,3 & 25,7 & 6,4 \\
\hline & BON7 & 21,1 & 0,12 & 0,02 & 20,8 & 22,7 & 1,9 \\
\hline & BON8 & 21,2 & 0,08 & 0,01 & 21,1 & 27,4 & 6,3 \\
\hline & BON9 & 20,6 & 0,07 & 0,01 & 20,4 & 24,8 & 4,4 \\
\hline \multirow{5}{*}{ 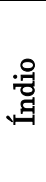 } & IND1 & 23,7 & 3,31 & 10,94 & 12,3 & 33,7 & 21,4 \\
\hline & IND2 & 22,6 & 0,42 & 0,17 & 21,7 & 25,3 & 3,6 \\
\hline & IND3 & 21,9 & 0,08 & 0,01 & 21,7 & 25,1 & 3,4 \\
\hline & IND4 & 21,7 & 0,11 & 0,01 & 21,5 & 23,3 & 1,8 \\
\hline & IND5 & 21,4 & 0,12 & 0,01 & 21,2 & 24,5 & 3,3 \\
\hline \multirow{5}{*}{ 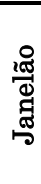 } & JAN0 & 23,2 & 4,64 & 21,51 & 7,9 & 37,7 & 29,8 \\
\hline & JAN1 & 22,1 & 2,39 & 5,71 & 11,5 & 29,0 & 17,5 \\
\hline & JAN2 & 22,4 & 2,75 & 7,58 & 13,0 & 39,0 & 26,0 \\
\hline & JAN3 & 22,0 & 1,79 & 3,22 & 14,3 & 28,1 & 13,8 \\
\hline & JAN4 & 22,1 & 1,66 & 2,75 & 15,2 & 26,7 & 11,5 \\
\hline \multirow{5}{*}{ 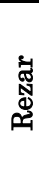 } & REZ1 & 24,3 & 3,38 & 11,45 & 13,9 & 35,4 & 21,5 \\
\hline & REZ2 & 23,7 & 1,26 & 1,59 & 17,9 & 26,3 & 8,4 \\
\hline & REZ3 & 24,0 & 0,74 & 0,54 & 20,9 & 27,8 & 6,9 \\
\hline & REZ4 & 23,8 & 0,58 & 0,34 & 21,1 & 25,4 & 4,3 \\
\hline & REZ5 & 24,1 & 0,42 & 0,18 & 22,8 & 27,2 & 4,4 \\
\hline
\end{tabular}

Fonte: Elaborado pelos autores, 2021. 
Para a Lapa Bonita é importante destacar que a distância entre os dois medidores, interno e externo, não ultrapassa 15 metros. No caso da Gruta do Janelão, chama atenção a amplitude elevada $\left(26,0^{\circ} \mathrm{C}\right)$ registrada pelo sensor JAN2. Este equipamento está instalado na porção mediana da caverna, na base de uma claraboia de grandes dimensões, formada pelo desabamento do teto da caverna, chamada Dolina dos Macacos. Esta abertura, considerada como uma outra entrada, confere a este setor da caverna uma maior susceptibilidade às variações do clima externo.

De acordo com Serafini-Júnior (2005), as características dos compartimentos geomorfológicos atuam como agentes de suporte às manifestações fisiográficas que envolvem as comunidades vegetais e humanas do PNCP. Partindo desta premissa, o autor propõe três unidades da paisagem consideradas homogêneas para o estudo do clima (Figura 4). O Planalto do São Francisco, unidade que compreende aproximadamente os limites geomorfológicos do Planalto das Gerais e Zona de Transição é o que apresenta, em média, os menores valores de temperatura e os maiores valores de umidade. $\mathrm{O}$ Compartimento Carstificado, região onde se encontram as cavernas deste estudo, apresenta valores intermediários de temperatura e umidade. A unidade Depressão do São Francisco corresponde à região com as temperaturas mais elevadas e menor umidade relativa do ar.

Lobo (2012) utiliza o termo "Zona Heterotérmica" para designar a região da caverna onde são mais perceptíveis os efeitos da influência atmosférica externa no microclima cavernícola. $\mathrm{O}$ posicionamento das estações de medição próximo às entradas das cavernas tem o objetivo de contribuir para a caracterização das condições climáticas neste setor da caverna.
Na Tabela 2, o equipamento CAR1 registra a menor temperatura média $\left(20,7^{\circ} \mathrm{C}\right)$ dentre todas as entradas das cavernas monitoradas. Ressalta-se que, tomando como referência o cânion do Rio Peruaçu, a Lapa do Carlúcio é a cavidade que se encontra mais próxima ao compartimento Planalto do São Francisco, região de temperatura mais amena. Por outro lado, verifica-se em REZ1 a maior temperatura média $\left(24,3^{\circ} \mathrm{C}\right)$ e a Lapa do Rezar é a que está mais próxima do clima mais quente da Depressão do São Francisco, situada bem à entrada do cânion do Peruaçu. A Figura 4 destaca inserção das cavernas no relevo e permite uma comparação entre os valores médios das temperaturas registradas nos sensores internos instalados mais próximos às entradas das cavernas. As diferenças na temperatura em função de alterações no relevo, percebidas por Serafini-Júnior (2005) ao estudar o ambiente externo no PNCP também podem ser observadas em relação ao salão de entrada. Os valores registrados nesta seção das cavernas, mostram uma discreta tendência $\left(R^{2}=0,3763\right)$ de aumento das temperaturas médias na medida em que se desloca do compartimento do Planalto dos Gerais para o compartimento da Depressão do São Francisco, descendo o curso do rio Peruaçu.

A análise das médias e do desvio padrão, evidencia o destaque que as variações da temperatura nas estações externas (BONO e JANO) e na região da entrada têm em relação às demais seções das cavernas (Figura 5). Nesta figura também é possível observar três padrões distintos em relação ao comportamento da temperatura interna. A Lapa do Carlúcio e a Gruta do Janelão apresentam em cada estação de medição os maiores valores de desvio padrão e temperaturas médias abaixo de $22,5^{\circ} \mathrm{C}$. 
Figura 4 - Unidades da paisagem utilizadas para o estudo do clima no PNCP (SERAFINI-JÚNIOR, 2005), com destaque para a disposição das cavernas monitoradas ao longo do cânion do rio Peruaçu e as respectivas temperaturas médias em cada entrada.

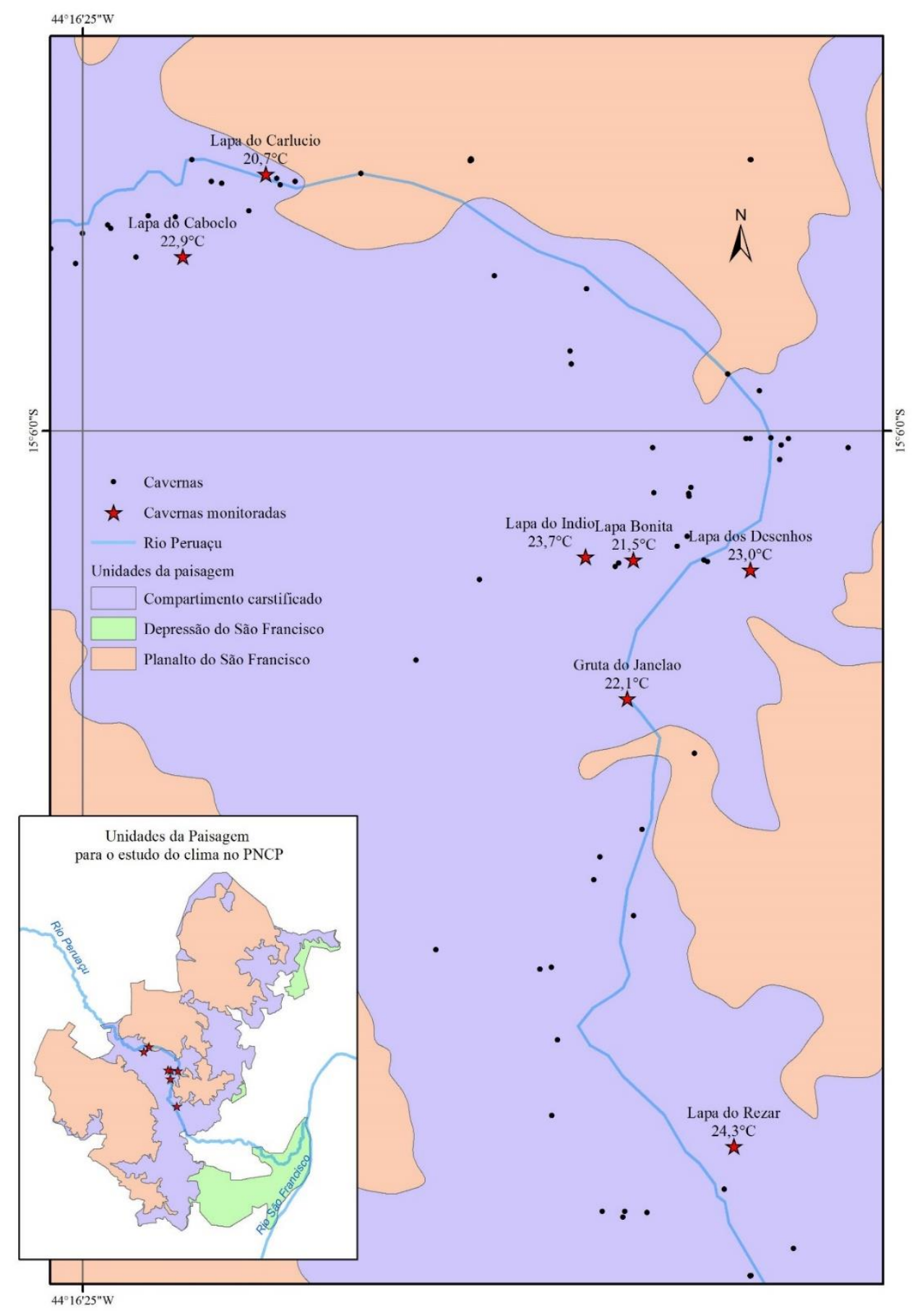

Fonte: Elaborado pelos autores, 2021. 
Figura 5 - Análise do desvio padrão em função das médias da temperatura para os dados coletados nas cavernas monitoradas.

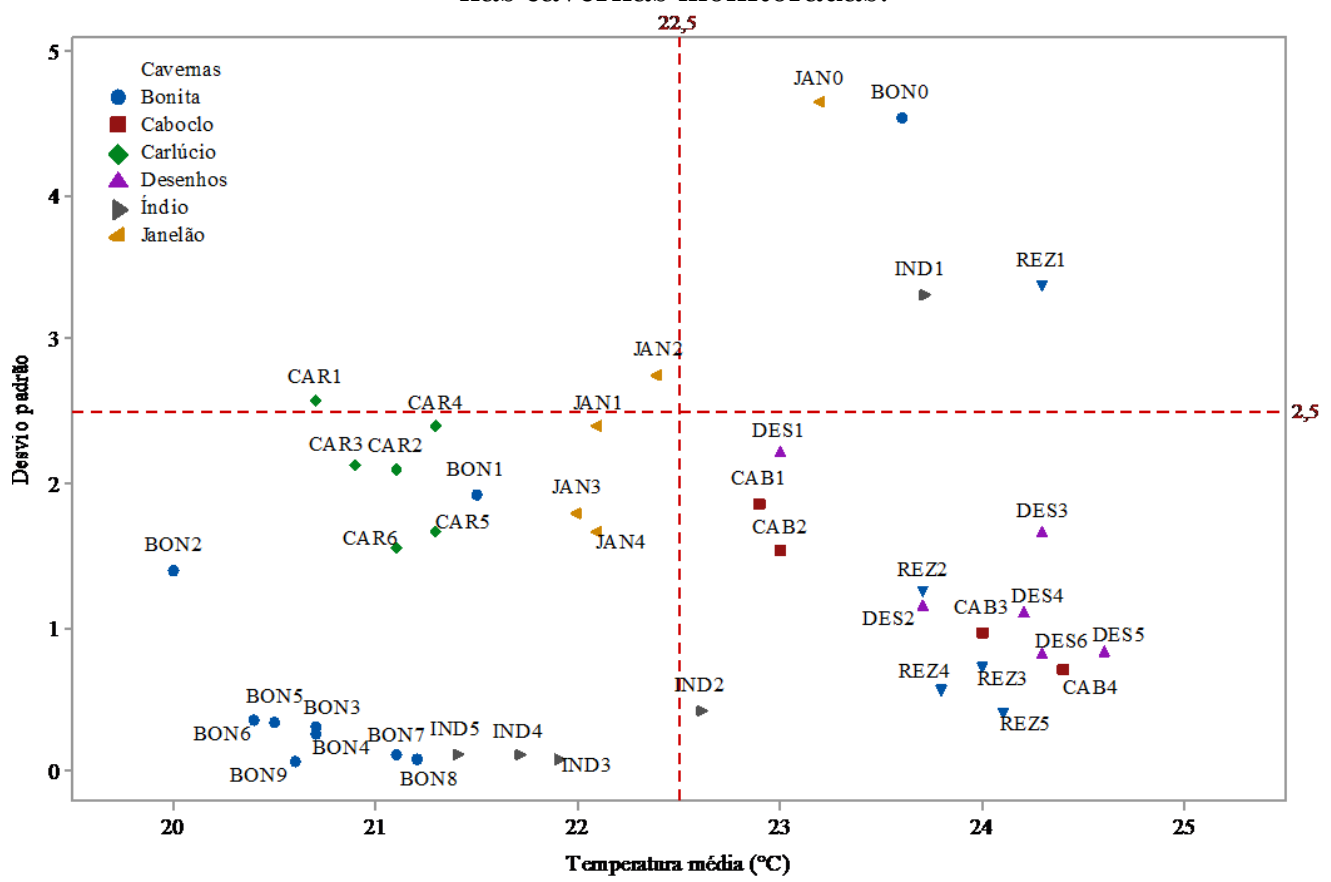

Fonte: Elaborado pelos autores, 2021.

A Lapa do Carlúcio (Figura 6) está localizada na média vertente do cânion do rio Peruaçu, em meio a mata ciliar presente na calha fluvial onde há a predominância de vegetação perenifólia em função da presença do rio (IBAMA, 2005). Este fator, aliado a sua proximidade com o compartimento do Planalto dos Gerais, influencia a ocorrência de temperaturas mais amenas, conforme identificado por Serafini-Júnior (2005). Os registros de temperatura da sua entrada (CAR1) apresentam um dos desvios padrão mais elevados $(12,40)$, porém sua temperatura média $\left(20,7^{\circ} \mathrm{C}\right)$ é a mais baixa quando comparada às entradas das demais cavernas. Esta caverna, com entrada de aproximadamente $20 \mathrm{~m}$ de altura e mais de $40 \mathrm{~m}$ de largura, é formada por um amplo conduto com $160 \mathrm{~m}$ de projeção horizontal. Seu trecho inicial tem altura aproximada de $30 \mathrm{~m}$ e $100 \mathrm{~m}$ de extensão. Após sofrer uma inflexão, este conduto se direciona para leste por mais $60 \mathrm{~m}$. Estas dimensões e a ausência de barreiras físicas significativas em seu interior favorecem as grandes variações de temperatura observadas em sua entrada.

Figura 6 - Vista aérea da entrada da Lapa do Carlúcio com destaque para a mata ciliar do rio Peruaçu ao fundo do cânion.

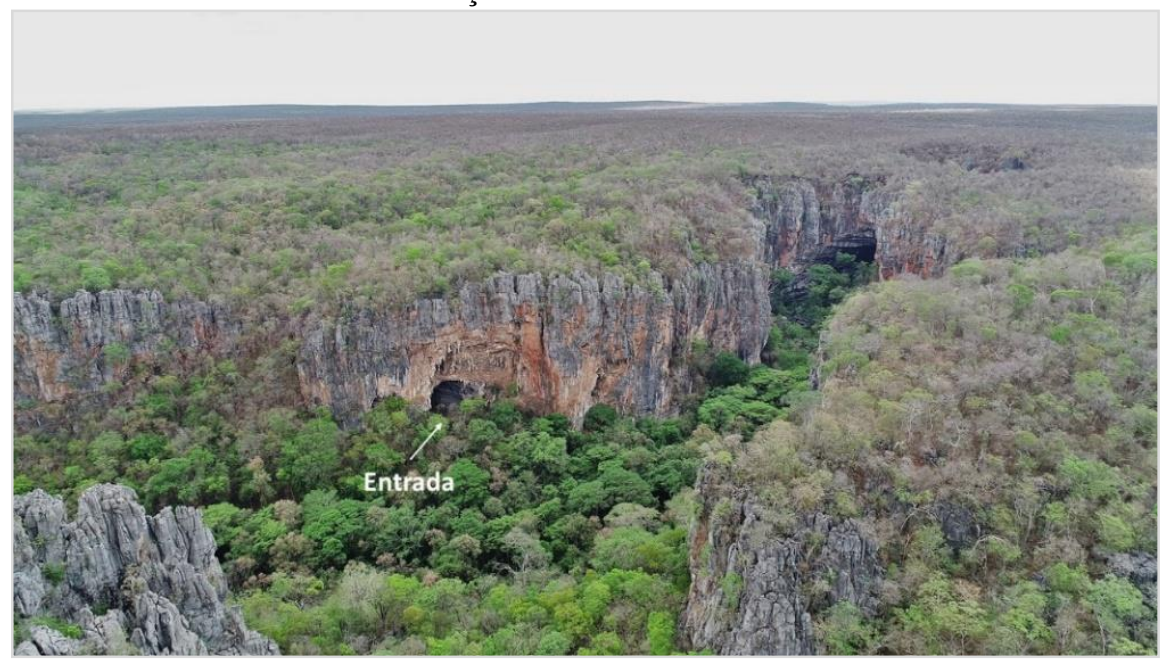

Fonte: Autores, 2021.

Assim como a Lapa do Carlúcio, a Gruta do Janelão também apresenta grande variação da temperatura média, indicando uma forte influência do clima externo em toda a extensão da caverna. Esta caverna apresenta setores com mais de $100 \mathrm{~m}$ de altura, chegando a $150 \mathrm{~m}$ de largura em alguns pontos e claraboias de dimensões 
expressivas. Estes atributos, aliados a presença do rio Peruaçu, contribuem para explicar a variação da temperatura em seu interior. Na Gruta do Janelão ainda merecem destaque as grandes variações observadas na estação JAN2. Dentre todas as cavernas monitoradas, esta é a única a possuir múltiplas entradas em função da presença das diversas claraboias. $\mathrm{O}$ equipamento em questão foi instalado no fundo da Dolina dos Macacos, próximo à margem esquerda do rio. Em função das expressivas dimensões da claraboia, este local recebe radiação solar direta durante várias horas dia, o que explica as grandes variações de temperatura e o registro da segunda maior temperatura $\left(39,0^{\circ} \mathrm{C}\right)$ dentre todas as estações de medição.

Ainda em relação à Figura 5, observa-se um outro padrão de comportamento, representado pelas Lapas Bonita e do Índio, caracterizado por apresentar as mais baixas temperaturas médias e também os menores desvios padrão. O comportamento das condições climáticas observado nestas duas cavernas é o que mais poderia se aproximar do modelo de zoneamento climático proposto por Lobo (2012). As duas cavernas estão localizadas na depressão da Fazenda Terra Brava, na base de um escarpamento calcário, onde chama a atenção uma extensa área de pastagem e uma faixa estreita de Mata Seca que faz a transição do pasto com o paredão (Figura 7). A Lapa Bonita possui $420 \mathrm{~m}$ de projeção horizontal e padrão retilíneo. O salão de entrada ocupa os primeiros $45 \mathrm{~m}$ do seu desenvolvimento e é onde estão instaladas as estações BON1 e BON2 (Figura 8). Estes dois equipamentos apresentaram desvio padrão com valores de 1,92 e 1,39, respectivamente, o que indica que esta seção da caverna apresenta ainda razoável influência do ambiente externo e poderia ser classificada como Zona Heterotérmica.

Figura 7- Vista aérea da entrada da Lapa Bonita localizada na depressão cárstica da Fazenda Terra Brava.

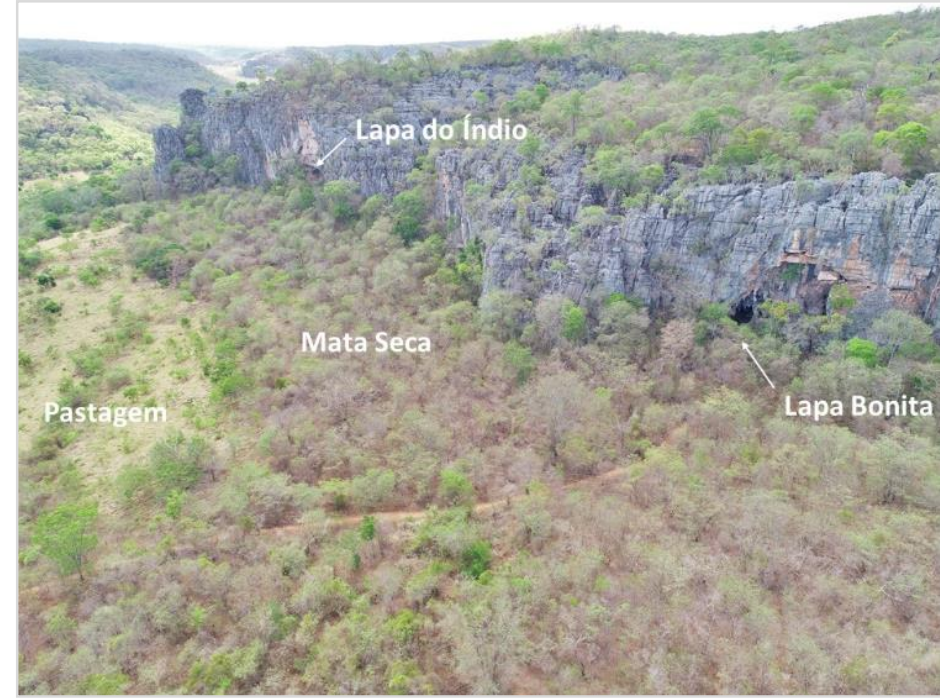

Fonte: Autores, 2021.

Após o local onde se encontra instalado BON2, a caverna apresenta um grande depósito de sedimentação química provocando um estreitamento significativo no conduto. Na sequência é possível acessar amplos salões onde estão localizados BON3, BON4, BON5 e BON6 onde foram registradas temperaturas médias mais baixas $\quad\left(20,7^{\circ} \mathrm{C}, \quad 20,7^{\circ} \mathrm{C}, \quad 20,5^{\circ} \mathrm{C}\right.$ e $20,4^{\circ} \mathrm{C}$ respectivamente) e os desvios padrão ficaram abaixo daqueles observados em seu salão de entrada $(0,31$, 0,26, 0,34 e 0,36, respectivamente), caracterizando o que poderia ser considerada a Zona Transacional Insaturada descrita por Lobo (2012). Já no terço final da caverna, após o local conhecido como Salão Vermelho, se encontra o setor com as menores variações de temperatura e onde estão instaladass BON7, BON8 e BON9. Este último segmento da caverna apresenta temperaturas médias um pouco acima daquelas observadas no trecho intermediário $\left(21,1^{\circ} \mathrm{C}, 21,2^{\circ} \mathrm{C}\right.$ e $20,6^{\circ} \mathrm{C}$, respectivamente) porém os valores permaneceram praticamente constantes durante todo o período investigado. Os baixos valores de desvio padrão observados em BON7 $(0,12)$, BON8 $(0,08)$ e BON9 $(0,07)$, contribuem para o que poderia ser considerado como a Zona Homeotérmica da Lapa Bonita. 
Figura 8- Distribuição espacial das estações automatizadas na Lapa Bonita. Fonte: Adaptado de IBAMA (2005).

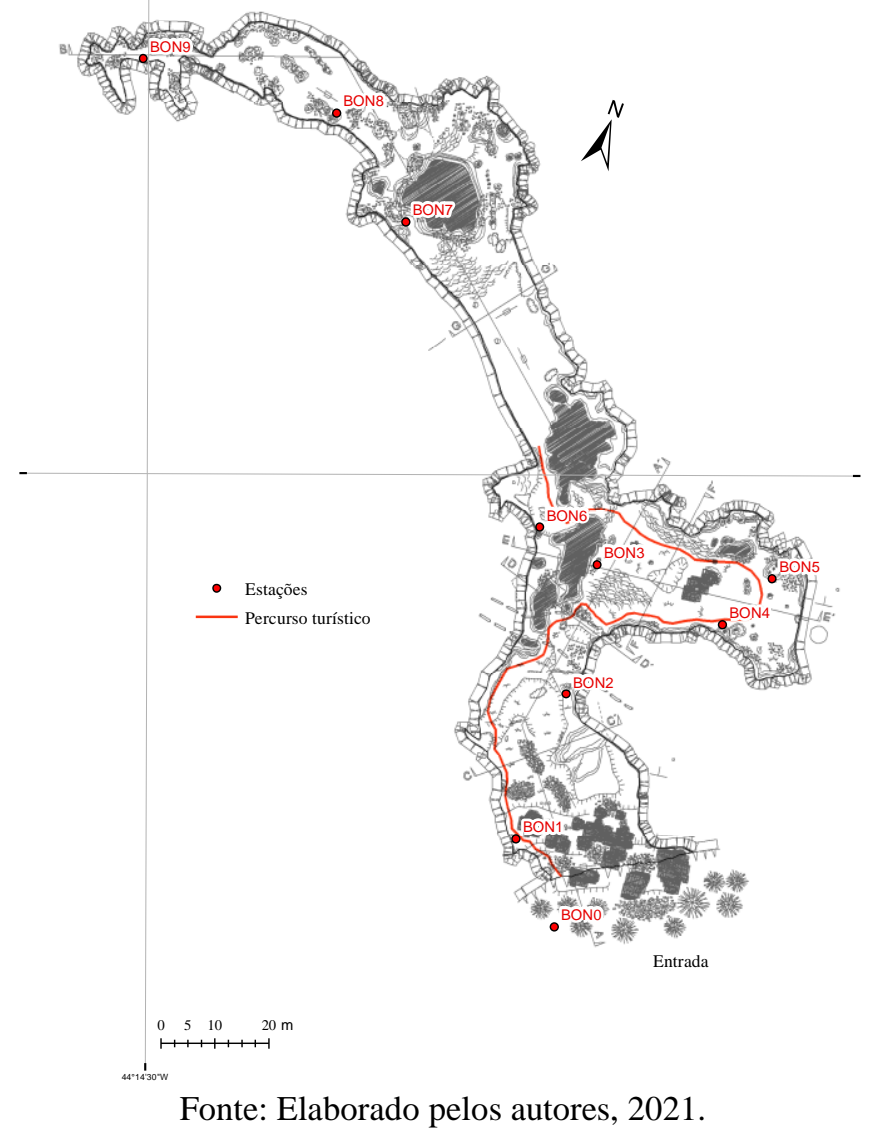

As observações referentes ao comportamento microclimático desta caverna, corroboram o os resultados apresentados por Gomes et. al. (2019) no que diz respeito à tendência de diminuição da influência climática externa à medida em que se distancia de sua entrada. Com dados mais consistentes, os resultados apresentados pela atual pesquisa também confirmam que os valores da temperatura e umidade relativa do ar apresentam variações muito menores do que aquelas observadas no ambiente externo.

Apesar de estar localizada bem próxima à Lapa Bonita (308 m), a Lapa do Índio está inserida em um ponto mais elevado do afloramento calcário, um pouco acima da copa das árvores, ficando assim sua entrada mais exposta à insolação e à circulação dos ventos. Estes fatores combinados com a presença de um teto baixo na entrada (inferior a $4 \mathrm{~m}$ ), contribuem para explicar o valor mais alto do desvio padrão em IND1 $(3,31)$, quando comparado com aquele observado em BON1 (1,92).

Assim como a Lapa Bonita, a Lapa do Índio tem um significativo estreitamento de conduto após o local onde se encontra instalada a estação IND1. Os registros obtidos neste equipamento permitem observar um desvio padrão bem maior do que aquele observado em IND2 $(0,42)$. Após este local, depois da transposição de outro trecho de teto baixo, se encontram os demais sensores, IND3, IND4 e IND5 que registraram valores ainda menores para o desvio padrão $(0,08,0,11$ e 0,12 , respectivamente).

O terceiro padrão de comportamento da temperatura pode ser observado nas lapas do Caboclo, dos Desenhos e do Rezar (Figura 5). Estas cavernas apresentam valores intermediários de desvio padrão quando comparados com as demais cavernas, demonstrando que a influência externa não é tão acentuada quanto aquela observada na Lapa do Carlúcio e Gruta do Janelão e nem tão discreta quanto a observada na Lapa Bonita e Lapa do Índio.

No que se refere à umidade relativa do ar, SerafiniJúnior (2005) destaca que no PNCP podem ser observados dois cenários distintos. O verão compreende os meses de dezembro a março e se refere a estação chuvosa. $\mathrm{O}$ inverno tem início em junho e término em setembro e se refere a estação seca. A Tabela 3 apresenta os dados coletados nas cavernas, agrupados considerando estes dois períodos. Ao se comparar os valores médios da umidade relativa do ar nos dois períodos, ficam evidentes as diferenças significativas entre o período chuvoso e o seco para quase todos os pontos amostrados. 
A única exceção é o último salão da Lapa Bonita, onde o valor da umidade relativa do ar permaneceu praticamente constante durante todo o período avaliado. $\mathrm{O}$ ambiente confinado, com aproximadamente $30 \mathrm{~m}^{2} \mathrm{de}$ área e altura inferior a 1,60 m, só se comunica com o restante da caverna por meio de um espaço centimétrico existente entre um conjunto de colunas, estalactites e estalagmites. Esta talvez seja a principal razão de terem sido observados valores tão baixos de desvio padrão no ponto BON9 (estação chuvosa 0,94 e estação seca 0,90 ) e valores muito altos de umidade relativa do ar, próximos aos $100 \%$, durante todo o período da pesquisa.

Tabela 3 - Registros da média da umidade relativa do ar discriminados por estações nos períodos chuvoso e seco.

\begin{tabular}{|c|c|c|c|c|c|}
\hline \multirow{2}{*}{\multicolumn{2}{|c|}{$\begin{array}{c}\text { Estações } \\
\text { automatizadas }\end{array}$}} & \multicolumn{2}{|c|}{ Período chuvoso } & \multicolumn{2}{|c|}{ Período seco } \\
\hline & & $\begin{array}{c}\text { Umidade média } \\
(\%)\end{array}$ & $\begin{array}{l}\text { Desvio } \\
\text { padrão }\end{array}$ & Umidade média (\%) & $\begin{array}{l}\text { Desvio } \\
\text { padrão }\end{array}$ \\
\hline \multirow{6}{*}{ 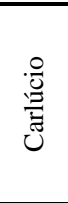 } & CAR1 & 83,5 & 10,65 & 66,7 & 9,23 \\
\hline & CAR2 & 82,5 & 10,08 & 64,6 & 8,33 \\
\hline & CAR3 & 82,6 & 10,10 & 65,4 & 8,56 \\
\hline & CAR4 & 81,9 & 12,14 & 64,7 & 10,38 \\
\hline & CAR5 & 80,6 & 10,17 & 62,2 & 8,42 \\
\hline & CAR6 & 82,4 & 10,44 & 63,0 & 7,96 \\
\hline \multirow{4}{*}{$\begin{array}{l}\overline{\tilde{D}} \\
\text { ठ } \\
\overline{\tilde{U}}\end{array}$} & CAB1 & 78,8 & 12,19 & 54,6 & 9,08 \\
\hline & $\mathrm{CAB} 2$ & 76,4 & 10,20 & 55,0 & 7,45 \\
\hline & CAB3 & 71,2 & 11,10 & 48,7 & 7,55 \\
\hline & CAB4 & 70,4 & 10,33 & 47,7 & 6,80 \\
\hline \multirow{6}{*}{ 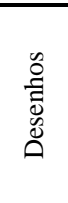 } & DES1 & 78,9 & 11,28 & 53,8 & 9,64 \\
\hline & DES2 & 72,7 & 10,72 & 48,4 & 7,82 \\
\hline & DES3 & 72,3 & 11,72 & 49,0 & 8,66 \\
\hline & DES4 & 71,7 & 10,56 & 48,2 & 7,61 \\
\hline & DES5 & 69,9 & 10,41 & 45,7 & 7,41 \\
\hline & DES6 & 71,9 & 10,68 & 47,4 & 7,34 \\
\hline \multirow{10}{*}{ 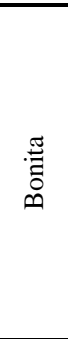 } & BON0 & 75,8 & 21,42 & 53,2 & 16,96 \\
\hline & BON1 & 83,1 & 11,02 & 60,0 & 9,83 \\
\hline & BON2 & 91,5 & 5,63 & 72,7 & 7,16 \\
\hline & BON3 & 91,7 & 1,39 & 68,7 & 5,99 \\
\hline & BON4 & 93,4 & 2,25 & 69,0 & 6,27 \\
\hline & BON5 & 96,2 & 2,08 & 74,1 & 6,23 \\
\hline & BON6 & 94,7 & 2,42 & 71,8 & 7,04 \\
\hline & BON7 & 91,8 & 1,43 & 71,0 & 5,39 \\
\hline & BON8 & 94,2 & 0,65 & 75,8 & 4,87 \\
\hline & BON9 & 98,9 & 0,94 & 98,7 & 0,90 \\
\hline \multirow{5}{*}{$\stackrel{\circ}{\stackrel{0}{\Xi}}$} & IND1 & 74,9 & 15,57 & 53,2 & 12,93 \\
\hline & IND2 & 80,4 & 9,35 & 60,0 & 8,59 \\
\hline & IND3 & 88,3 & 7,15 & 70,9 & 6,44 \\
\hline & IND4 & 87,2 & 8,26 & 70,7 & 7,75 \\
\hline & IND5 & 88,7 & 8,19 & 73,0 & 7,26 \\
\hline \multirow{5}{*}{ 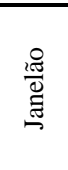 } & JAN0 & 79,7 & 19,55 & 57,0 & 17,41 \\
\hline & JAN1 & 82,7 & 11,76 & 64,1 & 10,70 \\
\hline & JAN2 & 80,7 & 10,67 & 66,5 & 9,73 \\
\hline & JAN3 & 83,2 & 9,34 & 63,8 & 9,14 \\
\hline & JAN4 & 82,7 & 9,17 & 63,1 & 8,31 \\
\hline \multirow{5}{*}{ 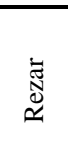 } & REZ1 & 73,6 & 18,26 & 53,6 & 14,03 \\
\hline & REZ2 & 72,3 & 10,92 & 51,5 & 8,48 \\
\hline & REZ3 & 70,3 & 9,75 & 52,1 & 7,76 \\
\hline & REZ4 & 69,3 & 9,19 & 48,8 & 6,86 \\
\hline & REZ5 & 71,0 & 10,37 & 48,2 & 6,87 \\
\hline
\end{tabular}

Fonte: Elaborado pelos autores, 2021.

Mesmo considerando as particularidades de cada caverna, observa-se que no período chuvoso (Figura 9a) praticamente todos os pontos amostrados apresentam valores relativamente elevados de umidade relativa do ar (acima de 70\%). Já no período seco (Figura 9b), exceto alguns pontos da Lapa Bonita e da Lapa do Índio que permaneceram acima dos $70 \%$, as demais estações registraram baixos valores de umidade relativa do ar, chegando próximo aos $45 \%$ nas Lapas dos Desenhos e do Caboclo.

Agrupamentos de cavernas também podem ser percebidos ao analisarmos os dados de umidade relativa do ar. Influenciados principalmente pelas condições externas, os sensores posicionados nas entradas da Lapa do Índio (IND1) e da Lapa Bonita (BON1) apresentam os maiores desvios padrão, quando comparados aos demais equipamentos instalados nestas cavernas, seja no período chuvoso (IND1=15,57 e BON1=11,02), seja na época da seca (IND1 = 12,93 e BON1=9,83). Porém, à medida em que se aumenta a distância em relação às entradas, as variações vão ficando cada vez menores. Esta condição possibilita reunir as duas cavidades em um grupo que se caracteriza por valores mais baixos do desvio padrão e umidade relativa do ar mais elevada, 
tanto no período chuvoso (Figura 9a), quanto no período seco (Figura 9b). Neste grupo merece destaque o comportamento observado na estação IND2 (desvio padrão igual a 9,35 no verão e 8,59 no inverno), que apesar de estar localizada após um estreitamento de conduto entre o salão de entrada e o segundo salão, ainda sofre grande influência externa. Lobo (2013) chama a atenção para a influência que o confinamento especial exerce na variabilidade dos parâmetros climáticos das cavernas. É possível destacar o comportamento observado na Lapa Bonita, onde uma obstrução existente entre o salão de entrada e o restante da caverna é o grande responsável por dificultar o processo de troca de energia com o meio externo. Esta característica é a grande responsável por manter a umidade acima de $90 \%$ durante a época das chuvas e em média acima dos $68 \%$ na época da seca. As Figuras 9a e $9 \mathrm{~b}$ também evidenciam os elevados valores de umidade relativa do ar e variações muito discretas no desvio padrão deste parâmetro observados na porção final da caverna (BON9) durante todo o período desta pesquisa. Portanto, este salão pode ser considerado como o ambiente que apresenta as condições mais homogêneas de temperatura e umidade relativa do ar dentre todos aqueles avaliados por esta pesquisa.

Ao verificarmos as médias de umidade relativa do ar das demais cavernas é possível identificar mais dois agrupamentos, além daquele representado pelas Lapas Bonita e do Índio. Um deles contém a Gruta do Janelão e a Lapa do Carlúcio com registros de umidade entre $83,5 \%$ e $80,6 \%$ no período chuvoso (Figura 9a) e 66,7\% e $62,2 \%$ no período seco (Figura 9b) que constituem o grupo com valores intermediários das médias de umidade relativa do ar. Neste conjunto, o que chama a atenção são valores muito parecidos para ambas as cavernas nas duas estações, revelando a pouca influência que o rio Peruaçu exerce na umidade relativa interna da Gruta do Janelão, ambiente de alta troca energética com o ambiente externo em função de múltiplas entradas (claraboias), além da presença do rio.

O terceiro conjunto de cavernas é composto pelos registros obtidos na Lapa dos Desenhos, Lapa do Rezar e Lapa do Caboclo, caracterizadas como as cavernas com os menores valores de umidade relativa do ar dentre aquelas pesquisadas. Neste grupo foram observados valores variando entre $78,9 \%$ e $69,3 \%$ no período chuvoso (Figura 9a) e $55,0 \%$ e $45,7 \%$ no período seco (Figura 9b). Convém ressaltar que dentre todas as cavernas pesquisadas, a Lapa do Rezar é aquela que se encontra mais próxima da Depressão do São Francisco (Serafini-Júnior, 2005) e estaria, portanto, mais susceptível à influência do clima mais seco desta unidade da paisagem do que as demais. Neste contexto, verificou-se que no equipamento instalado na entrada desta caverna (REZ1) foram observadas as menores médias de umidade relativa do ar dentre as entradas das três cavidades, $73,6 \%$ no período chuvoso e 53,6\% no período seco. Entretanto, as Lapas dos Desenhos e do Caboclo também apresentam valores tão baixos quanto a Lapa do Rezar e não se encontram tão próximas da unidade Depressão do São Francisco. Neste caso a explicação pode estar associada à morfologia das cavernas, pois ambas são caracterizadas por um conduto único e retilíneo e com comprimento inferior a 140 metros, sendo as menores cavernas pesquisadas. A ausência de grandes obstáculos favorece a circulação de ventos e a troca de energia com o ambiente externo. 
Figura 9 - Análise do desvio padrão em função das médias de umidade relativa do ar para os dados coletados nas cavernas monitoradas. a) Período chuvoso e b) Período seco.
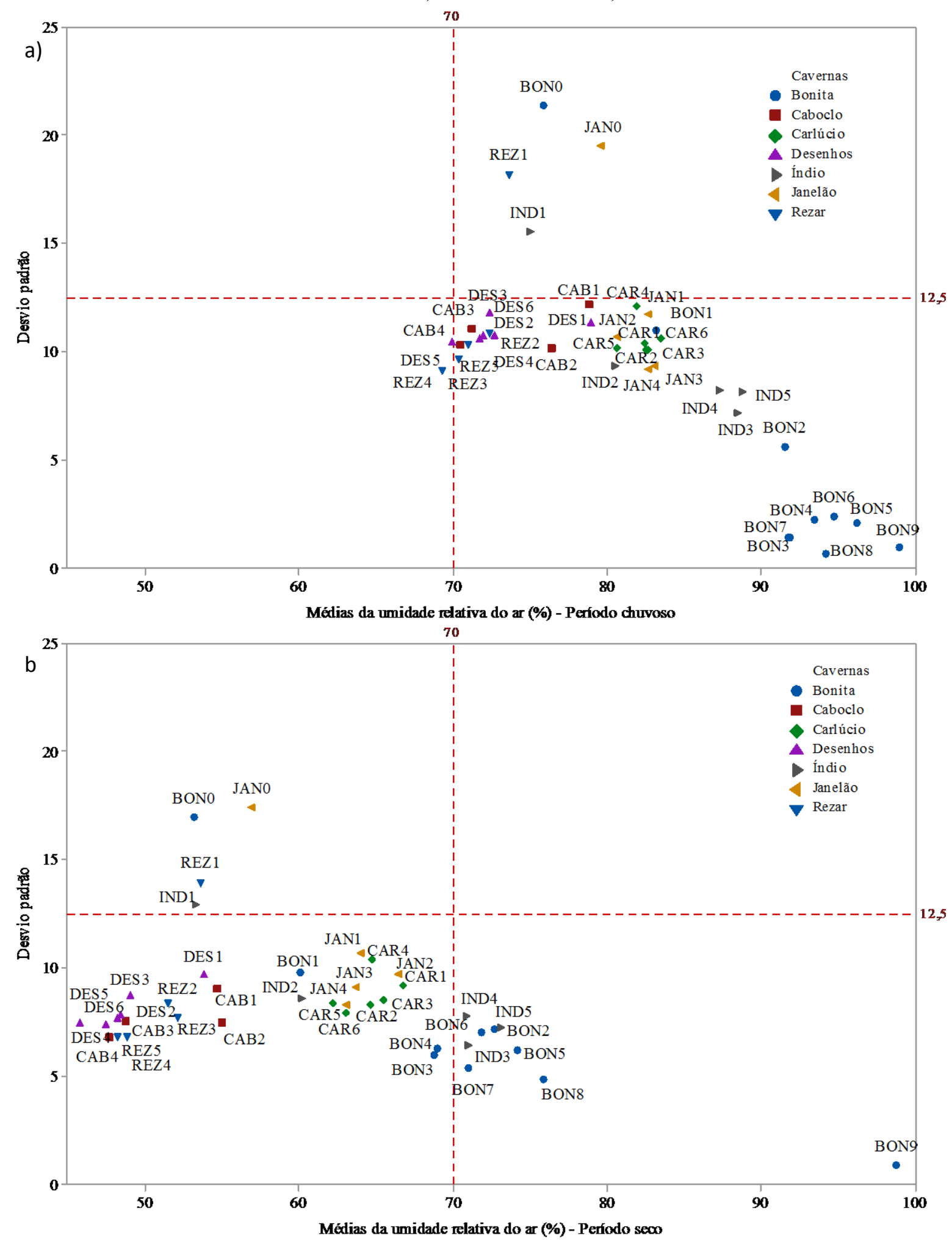

Fonte: Elaborado pelos autores, 2021.

\section{CONSIDERAÇÕES FINAIS}

O vale cárstico do rio Peruaçu e os diversos atributos (espeleológico, paisagístico, cultural, arqueológico e paleontológico) associados a ele, compõem um dos conjuntos naturais mais representativos do país. A singularidade e relevância destas características suscita a importância de implantação de medidas de 
monitoramento com vistas à compatibilização entre o uso turístico dos recursos e sua conservação.

Minas Gerais é atualmente o estado com o maior número de cavernas conhecidas no Brasil e esta pesquisa é pioneira no estado, não apenas por reunir dados coletados ao longo de pouco menos de três anos, mas também por considerar muitas cavernas monitoradas simultaneamente. Ao observarmos a distribuição espacial das pesquisas relacionadas ao microclima cavernícola no território brasileiro, este estudo também se destaca por ser uma dos únicos no país a estudar o comportamento do microclima cavernícola em cavernas situadas em zonas climáticas mais áridas.

Deste modo, ao realizar a caracterização microclimática de sete das onze cavernas que integram o roteiro turístico do PNCP, o presente trabalho apresenta subsídios para aprimorar as diretrizes de visitação destes atrativos, bem como o redimensionamento dos roteiros internos de visitação. Além desta contribuição, é importante destacar que a proposta metodológica de monitoramento do microclima cavernícola poderá servir como referência para a elaboração do Programa de Monitoramento das Condições Ambientais das Cavernas previsto no plano de manejo da UC. Até o final do ano de 2019 esta pesquisa já havia gerado mais de 4 milhões de registros de temperatura e umidade relativa do ar. O projeto tem término previsto para o final do ano de 2022, o que permitirá a formação de uma base de dados robusta e o desenvolvimento de diversos produtos para subsidiar o uso público dos atrativos do PNCP como, por exemplo, o zoneamento microclimático das cavernas.

Os resultados alcançados nesta pesquisa confirmam a influência externa no comportamento do microclima cavernícola já evidenciada em cavernas de países de clima temperado e em outras regiões do Brasil de clima mais ameno. Também foi observada a tendência à estabilidade microclimática nos salões mais distais das cavidades. Apesar do aumento do número de turistas nas cavernas do PNCP, a coleta dos dados de visitação ainda é muito insipiente. Informações relacionadas aos horários de entrada e saída das cavernas, bem como a quantidade de pessoas que efetivamente adentram as cavidades ainda necessitam ser mais bem apuradas. Neste sentido, estão sendo desenvolvidas ações junto a equipe gestora da UC e aos condutores que atuam na unidade para que este processo seja aprimorado. Desta forma, até o término do projeto em 2022, será possível a obtenção de dados confiáveis que possibilitarão o desenvolvimento de estudos mais aprofundados para verificar qual a influência da presença humana no comportamento da temperatura e umidade relativa do ar nas cavernas do PNCP.

\section{AGRADECIMENTOS}

Os autores agradecem a equipe do Parque Nacional Cavernas do Peruaçu e aos condutores ambientais que atuam na unidade de conservação pelo apoio prestado durante o desenvolvimento da pesquisa. U.A. Ruchkys e L.E.P. Travassos agradecem ao CNPq pela Bolsa de Produção em Pesquisa.

\section{REFERÊNCIAS}

BADINO, G. Underground meteorology-"What's the weather underground?” Acta Carsologica, v. 39, n. 3, p. 427-448, 1 dez. 2010. https://doi.org/10.3986/ac.v39i3.74

BOGGIANI, P. C. et. al. Definição de capacidade de carga turística das cavernas do Monumento Natural Gruta do Lago Azul (Bonito, MS). Geociências, v. 26, n. 4, p. 333348,2007

BRASIL. Decreto s/no de 21 de setembro de 1999, 1999.

CALAFORRA, J. M. et al. Environmental control for determining human impact and permanent visitor capacity in a potential show cave before tourist use. Environmental Conservation, v. 30, n. 2, p. 160-167, jun. 2003. https://doi.org/10.1017/S0376892903000146

CECAV. Base de dados geoespacializados das cavernas do Brasil. Disponível em: https://www.icmbio.gov.br/cecav/images/stories/downlo ads/Base_de_dados/cav_canie_31122020.zip. Acesso em: 19 jan 2021

CIGNA, A. A. Environmental management of tourist caves. Environmental Geology, v. 21, n. 3, p. 173-180, 1993. https://doi.org/10.1007/BF00775302

GOMES, M. et al. Monitoramento microclimático de grutas turísticas de Minas Gerais: estudo de caso da Lapa Bonita, Parque Nacional Cavernas do Peruaçu. $35^{\circ}$ Congresso Brasileiro de Espeleologia. Anais...Bonito, MS: Sociedade Brasileira de Espeleologia, 2019.

IBAMA. Parque Nacional Cavernas do Peruaçu - Plano de manejo. Brasília, DF: Instituto Brasileiro do Meio Ambiente e dos Recursos Naturais Renováveis, 2005.

KOHLER, H. C.; PILÓ, L. B.; MOURA, M. T. T. Aspectos geomorfológicos do Sítio Arqueológico Lapa do Boquete. Anais do $3^{\circ}$ Congresso da ABEQUA. Anais...Rio de Janeiro, RJ: 1989

LOBO, H. A. S. Histórico das pesquisas espeleoclimáticas em cavernas brasileiras. Espeleo-Tema, v. 21, n. 2, p. 131144,2010

LOBO, H. A. S. Estudo da dinâmica atmosférica subterrânea na determinação da capacidade de carga turística na Caverna de Santana (PETAR, IporangaSP). Rio Claro, SP: Tese (Doutorado em Geociências e Meio Ambiente). Universidade Estadual Paulista, 2011.

LOBO, H. A. S. Espeleoclima e suas aplicações no manejo do turismo em cavernas. Revista do Departamento de Geografia da USP, v. 23, p. 27-54, 2012

LOBO, H. A. S. Circulação microclimática entre superfície, grandes dolinas e cavernas no carste de São Desidério, Bahia. Sociedade \& Natureza, v. 25, n. 1, p. 163-177, 2013. 45132013000100013

LOBO, H. A. S..; BOGGIANI, P.; PERINOTTO, J. Speleoclimate dynamics in Santana Cave (PETAR, São Paulo State, Brazil): general characterization and implications for tourist management. International Journal of Speleology, v. 44, n. 1, p. 61-73, jan. 2015. https://10.5038/1827-806X.44.1.6

MOURA, M. T. T. A evolução do sítio arqueológico Lapa do Boquete na paisagem cárstica do Vale do Rio 
Peruaçu: Januária (MG). São Paulo, SP: Universidade de São Paulo, 1997.

PILÓ, L. B. A morfologia cárstica do baixo curso do Rio Peruaçu, Januária,Itacarambi-MG, 1989. Belo Horizonte, MG: Universidade Federal de Minas Gerais, 1989.

PILÓ, L. B.; RUBBIOLI, E. Cavernas do Vale do Rio Peruaçu (Januária e Itacarambi), MG. In: SCHOBBENHAUS, C et al. (Eds.). Sítios Geológicos e Paleontológicos do Brasil. Brasília, DF. DNPM. 2002 p. 453-460. Disponível em:< http://sigep.cprm.gov.br/sitios.htm>. Acessado em 23/11/2020.

PULIDO-BOSCH, A. et al. Human impact in a tourist karstic cave (Aracena, Spain ). Environmental Geology, v. 31, n. June, p. 142-149, 1997. https://doi.org/10.1007/s002540050173

ROCHA, B. N. Estudo microclimático do ambiente de cavernas , Parque Estadual Intervales, SP. São Paulo, SP: Dissertação (Mestrado em Geografia Física) Universiade de São Paulo, 2010.

ROCHA, B. N.; GALVANI, E. Mcroclima de ambientes cavernícolas: Estudo de caso da Gruta da Santa, Parque Estadual de Intervales, SP. Revista Brasileira de Climatologia, n. 9, p. 21-34, 2011 http://dx.doi.org/10.5380/abclima.v9i0.27508

SANTOS, D. J. et al. Microclimatic monitoring of caves open for tourism at the Cavernas do Peruaçu National Park, Minas Gerais, Brazil. (M. Prelovšek, Ed.) 26th International Karstological School "Classical Karst". Anais...Postina: Scientific Research Centre of the Slovenian Academy of Sciences and Arts, Karst Research Institute, 2018. Disponível em: <https://iks.zrcsazu.si/en/archive/> Acessado em 23/11/2020.

SCHOBBENHAUS, C.; NEVES, B. B. B. A geologia do Brasil no contexto da Plataforma Sul-Americana. In: BIZZI, L. A. et al. (Eds.). . Geologia, Tectônica e Recursos Minerais do Brasil. Brasília, DF: CPRM, 2003. p. 55

ŠEBELA, S.; PRELOVŠEK, M.; TURK, J. Impact of peak period visits on the Postojna Cave (Slovenia) microclimate. Theoretical and Applied Climatology, v. 111 n. $1-2$, p. 51-64, 18 jan. 2013 https://doi.org/10.1007/s00704-012-0644-8

ŠEBELA, S.; TURK, J. Natural and anthropogenic influences on the year-round temperature dynamics of air and water in Postojna show cave, Slovenia. Tourism Management, v. 40, p. 233-243, 2014. https://doi.org/10.1016/j.tourman.2013.06.011

SERAFINI-JÚNIOR, S. Delimitação de unidades climáticas locais no Parque Nacional Cavernas do Peruaçu. São Paulo, SP: Dissertação (Mestrado em Climatologia). Departamento de Geografia. Universidade de São Paulo, 2005.

TOOMEY, R. S. III. Geological monitoring of caves and associated landscapes, in Young, R., and Norby, L., Geological Monitoring: Boulder, Colorado, Geological Society of America, p. 27-46, 2009. https://doi.org/10.1130/9780813760322.

TRAVASSOS, L. E. P. A importância cultural do carste e das cavernas. Belo Horizonte, MG: Tese (Doutorado em Tratamento da Informação Espacial) - Pontifícia Universiade Católica de Minas Gerais, 2010.

TRAVASSOS, L. E. P. Assesment of natural and atropogenic process in micrometeorology of Postojna cave system by numerical models and modern methods of data aquisition and transfer. Postojna: Pontificial Catholic University of Minas Gerais \& Research Centre of the Slovenian Academy of Sciences and Arts, 2016.

UNESCO. Unided Nations Educational, Scientific and Cultural Organization. World Heritage Centre, Global Strategy. 2020. Disponível em : https://whc.unesco.org/en/tentativelists/1124/. Acessado em 23/11/2020.

VERÍSSIMO, C. U. V et al. Microclima e espeleoturismo na Gruta de Ubajara, CE. In: Congresso Brasileiro de Espeleologia. 27., 2003. Anais...Januária, MG: Sociedade Brasileira de Espeleologia, 2003.

\section{CONTRIBUIÇÃO DOS AUTORES}

M.G. Concepção do estudo, coleta e análise de dados e redação do texto. D.J.S. Coleta e análise de dados e redação do texto. U.R.A e L.E.P.T. Coleta de dados e redação do texto. 